\title{
Community Practices and Locative Media
}

\author{
Katharine S. Willis \\ Locating Media Project \\ University of Siegen \\ +491704113485 \\ willis@locatingmedia.uni- \\ siegen.de \\ Pablo Abend \\ Locating Media Project \\ University of Siegen \\ +491792132421
abend@locatingmedia.uni- siegen.de

\author{
Keith Cheverst \\ Dept. Computing \\ InfoLab21 \\ Lancaster University \\ $+441524510312$ \\ kc@comp.lancs.ac.uk \\ Cornelius Neufeldt \\ Information Science and New Media, \\ Institute for Information Systems \\ University of Siegen \\ +49271740 4076 \\ cornelius.neufeldt@uni- \\ siegen.de \\ Claudia Mueller \\ CSCW in Organisations, Institute for \\ Information Systems \\ University of Siegen \\ +49271740 4076 \\ claudia.mueller@uni-siegen.de
}

\begin{abstract}
The development of locative media applications is not simply about the physical location or social setting in which the interaction occurs, but rather about situating the media within a community of practice. This workshop will provide the environment for researchers to explore the potential for locative media applications to support community practices. The workshop will highlight the many open areas that require research attention, identify key problems that need to be addressed, and also discuss approaches for solving these issues. In particular the workshop will focus on appropriate methodologies for identifying requirements, evaluating behaviour and integrating locative media in specific real-world community structures.
\end{abstract}

\section{Categories and Subject Descriptors}

D.2.1 [Requirements/Specifications], H.5.3 [Group and Organization Interfaces]

\section{General Terms}

Performance, Design, Human Factors.

\section{Keywords}

Media, locating, community, ethnography, practices.

\section{INTRODUCTION}

Many studies have investigated how mobile computing can respond dynamically to the setting in which the interaction occurs. This refers to how such media can be 'located' within the setting. Locative media has tended to refer to media which respond directly to location and features of spatial settings [1] but in this paper we refer to locative media as those which are embedded

Copyright is held by the author/owner(s).

MobileHCI09, September 15 - 18, 2009, Bonn, Germany.

ACM 978-1-60558-281-8/09/09. within a social framework or setting. This setting may have space as a key aspect of the interaction, but the social network or community in which it is embedded is the primary factor. A good deal has been written on the subject of social collaboration among individuals using communication devices, and what conditions or features are required to enable such activities [e.g. 2]. In a similar vein the work of Brown and colleagues, underline the importance of location in social practices in research where they investigate the settings in which people interact, and define the term "location-in-interaction"; an emotional, accountable and even moral part of family life [3]. A project by Giles et al. explores how place-based cultural knowledge can be shared using a guest and host framework [4]. A number of researchers have sought to investigate the existing qualities and features of community practices in order to provide insights into how media can be located within these existing structures. Taylor et al. describe a technology probe in the form of simple photo gallery aimed at understanding how digital displays can help support communities through the display of user-generated photos and videos [5].

With its focus on the situated nature of interaction and the social character of use, ethnography is a valuable method for understanding how mobile computing can become embedded within a wide variety of social settings. A number of researchers have developed a method originally proposed by Gaver, called cultural probes [6]. For instance Cheverst et al. approached the challenge of designing technology interventions for a residential care setting by combining the use of cultural probes, technology probes and participatory design workshops [7]. Doerner et al. have extended cultural probes with what they term infrastructure probes [8], in order to improve the collaboration between users and developers. Their infrastructure probes consist of a screenshot tool, a digital camera, Post-it's etc. Alternatively, Buescher et al. propose a 'bricolage' approach [9] that involves users, participatory designers and ethnographers in a continuing cycle of design and revised work practice.

\section{MOTIVATION}

There has been much design of applications of locative media in urban settings, such as LBS, location-based gaming and mobile social software applications, but little which investigates the use and integration of such media within existing community 
structures and practices. There are many problems inherent in studying an intangible concept such as community and how to evaluate whether a design has succeeded in supporting or improving notions of community [10]. Everyday social interactions within a community are not necessarily either explicit or even consciously recognized by those members of the community.

Mobile computing itself poses practical problems for data gathering and anlaysis, For instance, users are mobile; they move across extended physical areas, quickly at times, sometimes even running, which can make it difficult to document their action and capture video material. Furthermore, certain communities are inherently mobile which can further exacerbate the problems associated with effective ethnographic study. For example, Axup et al. encountered numerous difficulties when attempting to study a community of backpackers with a view to supporting appropriate technology design [11].

There are new challenges to established ethnographic methods from both standpoints: capturing the temporary nature of the practices with mobile media, but also extracting the intricate web of strong and weak social ties and relationships, in order to understand community practices is a challenging issue. Consequently there is still much room for development, and the full potential of such methodologies needs to be explored.

\section{AIMS}

- How can mobile media be located within existing communities and social settings?

- How can we find better ways of enabling and supporting locative media in community practices?

- How can mobile media foster communities and facilitate daily living, such as for communities in rural areas or the elderly?

- How can ethnographic methods inform and evaluate the place and integration of media in community settings?

\section{AUDIENCE}

The workshop seeks contributions from researchers from a diverse range of interdisciplinary fields, such as HCI, CSCW, sociology, architecture, ethnography and media studies.

\section{WORKSHOP PLAN}

Prior to the workshop we will widely publicise and generate enthusiasm about the workshop to a broad inter-disciplinary community through related email newsletters and at http://www.uni-siegen.de/locatingmedia/workshop.html. The actual workshop will consist of two stages, the first an exploratory session where participants will briefly present their position papers. The second session will encourage active discourse on the issues raised by the position papers, and will include a practical session. Extended versions of the papers will be considered for publication in an edited volume.

\section{ORGANISER BACKGROUNDS}

Katharine S. Willis's research interests lie in understanding how media is embedded in spatial and social settings. She has authored a number of publications in this area, and in 2007 she successfully co-organised a workshop at CHI entitled: Shared Encounters. She is currently a researcher on the Locating Media Project at University of Siegen.

Keith Cheverst is a senior lecturer at Lancaster University and one of his research interests is investigating the effectiveness of technology probe based approaches for supporting the inclusive design of ubicomp and mobile technologies that support coordination and community in a variety of settings. He has coorganised a number of worksops in this area.

Claudia Müller is a research assistant in the research group "CSCW in Organisations" and $\mathrm{PhD}$ candidate at the Graduate School "Locating Media", both at University of Siegen. As a cultural and medical anthropologist she works on ethnographically-informed technology development in complex and dynamic settings.

Pablo Abend is a PhD candidate at the Graduate School "Locating Media" at University of Siegen. His background is communication science and media studies and his main research interests are Geomedia, Neogeography, Social Networking Services and ICTs in mobile environments.

Cornelius Neufeldt is a research assistant in the research group "Information Systems and New Media" and PhD candidate at the Graduate School "Locating Media", both at University of Siegen. He has a background in information science and management and his research interests are ubiquitous computing, ICT in domestic and mobile environments and interactive TV applications.

\section{ACCEPTED PAPERS}

The full version of the workshop papers are available to download as pdf's at:

http://www.uni-siegen.de/locatingmedia/workshop.html

\subsection{Map-Based Wikis as Contextual and Cultural Mediators}

Barbara R. Barricelli, Claudia Iacob, Li Zhu

Dipartimento di Informatica e Comunicazione, Università degli Studi di Milano

Abstract: In this paper, we introduce map-based wikis describing the contextual and cultural mediation performed by them. Such virtual interactive systems allow users, having different cultural backgrounds, different expertise and roles, and using different devices, to create and manage a shared knowledge base. The mediation activity made by map-based wikis is cultural in that users that belong to different cultures and speaking different languages can access the same knowledge base and share their knowledge with the others, and contextual because of the ability of the system to mediate between users acting different roles and between users that access the system with different devices, mobile and desktop. The discussion is made concrete by the example of Valchiavenna BANCO Prototype.

\subsection{The Transborder Immigrant Tool: Violence, Solidarity and Hope in Post-NAFTA Circuits of Bodies Electr(on)/ic}

Micha Cardenas, Amy Sara Carroll, Ricardo Dominguez, Brett Stalbaum

EDT, Calit2, B.A.N.G. Lab, UCSD/Michigan

Abstract: This polyvocal, collectively authored paper describes the Transborder Immigrant Tool, a border disturbance art project 
developed by the Electronic Disturbance Theater. The paper outlines the motivations behind the tool and elaborates a notion of Science of the Oppressed as a methodology for developing locative media projects in solidarity with social movements. A shift is identified from Tactical Media to Tactical Biopolitics in contemporary media art. Walkingtools.net is also introduced as a platform for sharing technical information about locative media projects in order to create an ecology of projects. Poetic sustenance, part of the Transborder Immigrant Tool's functioning, is discussed in a context of Inter-American Transcendentalism.

\subsection{Localized Communication with Mobile Devices}

Dennis Dunekacke, Oliver Schnabel, Helmut Eirund, Matthias Stock, André Peschel, Thorsten Teschke

Media Computer Science, University of Applied Sciences Bremen Abstract: Tagging has been applied in many projects for the purpose of locating users and providing information about locations to users. Mutual interaction between different users visiting the same location at different times, however, has been neglected. This paper presents the NewsFlush system which has been developed in student projects at University of Applied Sciences Bremen. The approach followed in NewsFlush is to foster asynchronous location-based communication by both a mobile and a web application. Emphasis is put on the visualization of dialog structures resulting from this communication.

\subsection{Urban Encounter: Location-Based Collective Storytelling}

Thierry Giles ${ }^{1}$, Michael Marianek ${ }^{2}$, Sarah K. Freidel ${ }^{3}$

${ }^{1} \mathrm{~K} 3$ School of Art, Culture and Communication Malmö University

${ }^{2}$ Bauhaus University of Weimar

${ }^{3}$ Architect, Ny Ny, USA

Abstract: In this paper, we describe the workshop activity; Urban Encounter, which creates opportunities to discuss common narratives of places through a street game experience. The workshop is base on the concept of place-based storytelling where participants assume both the role of Guest and Host of the story. Participants of the workshop creates personalized adventure route through a space defined by the organizer and publishes it to a digital map. Each collected stories are merge into a main adventure route. The participants then have the opportunity to reexplore the known space through an unraveling of a series of clues left by the other host, which lead them through a particular spatial experience. The treasure at the end of the game is not a material reward but rather the construction of a shared social experience; the exploration and revealing of each individual stories developing as a valuable artifact in the memory of all game participants. The workshop measures its outcome with an open discussion on sharing common stories of a place, and in particular those that support the construction of social framework.

\subsection{From "World Wide Web VIP" to "Tutor" and Vice Versa \\ Olga Kisseleva \\ Professor, Director, Art\&Science Program, University of Paris 1 Pantheon-Sorbonne, Faculty of Arts}

Abstract: TUTOR project is a work in progress I developed in 2006-2007 in Bilbao and in San Sebastian(Spain) within the framework of DISONANCIAS. DISONANCIAS is an interdisciplinary project founded in 2005 by Xabide Group to promote the relationship between artistic creativity and technological innovation and to establish a new dialogue between the business world (and its technological environment), the artist world (and its creative development) and society, the ultimate beneficiary of the results of innovation.

\subsection{The Mogi location-aware community and its interaction order: "Augmented" face-to- face encounters as rare, public performances}

Christian Licoppe, Yoriko Inada

Department of Social Science, Telecom ParisTech

Abstract: We analyze here the interaction order of a locationaware community playing a location-based game, Mogi. We show how players usually separate their involvement in the game from other engagements, so that as a group they behave like a community of ,real life' strangers, relating to one another almost only through the game locative and communication media. This enables them to avoid certain unwanted consequences which the publicity of locations (a core feature of the Mogi experience) might entail. Relationships develop within the game and are usually kept there, subverting the primacy of face-to-face encounters which underlies our usual understanding of what social life is about. Face-to-face meetings between players are relatively rare events. When the participants remain logged on to the game, such encounters, potentially heralded by precursor ,mediated coproximity events' become public, collective performances to be seen, appreciated, commented on and gossiped about by an audience of , distant onlookers'.

\subsection{Friend or Fiend: Co-creation at Coolhaven-island}

Justien Marseile ${ }^{1},{ }^{2}$, Ingrid Mulder ${ }^{1},{ }^{3}$

${ }^{1}$ School of Communication, Media \& IT Rotterdam University, ${ }^{2}$ The Future Institute, Rotterdam

${ }^{3}$ ID-StudioLab Delft University of Technology

Abstract: Often, technology is seen as a threat, e.g., privacy, identity theft, rather than a friend enhancing social inclusion. In the current project, students were enticed to design for social cohesion in Coolhaven, one of Rotterdam's neighborhoods wellknown for social, economical, and cultural deprivation. Within the theme 'friend or fiend' students practiced co-creation techniques with local citizens to understand societal dynamics. After communicating these community insights with local government, concepts were developed that remove barriers between citizens by making use of geo-data; for this, subgroups that usually are not linked due to their diverse backgrounds or lifestyles were selected, e.g., elderly, students, or drifters. We report on the co-creation process as well as the resulting concepts of locative media.

\subsection{Challenges towards the Design of Locative Media for Supporting Interaction Spaces for the Ageing Society}

Claudia Müller ${ }^{1}$, Cornelius Neufeldt ${ }^{1,}$ Sebastian Sawatzki ${ }^{2}$

${ }^{1}$ Locating Media Project University of Siegen

${ }^{2}$ Information Systems and new Media, University of Siegen 
Abstract: The position paper highlights challenges when applying ethnography within the design process of ICT for the ageing society. We show that an in-depth investigation of the every-day life of the elderly is essential. Especially when regarding the fact that we cannot talk about the elderly as one homogeneous group but rather as individuals. In our paper we present an early approach on eliciting relevant aspects which have to be taken into account when designing for the ageing society. These are aspects which help to identify and operationalise the different groups and their needs and by this help to design technologies which better meet the needs of the target groups. However this position paper focuses primarily on an aspect which is only seldom addressed though, drawing on our experience, it is an aspect which should be brought to the discussion board: the barriers and challenges of getting access to the field in focus for applying an ethnography-based design approach. Grasping an adequate communication mode from researcher to the prospective design process participants is inherently linked to individual conducts of life.

\subsection{Social-Technical Implications Establishing a Mesh Network within an Inter- Cultural Neighborhood}

Kai Schubert

University of Siegen

Abstract: This text is describing the establishment of a mesh network of the inter-cultural computer clubs "come_IN". This idea of a mesh network that covers the whole neighborhood of a city results from experience within the project "come_IN" in Germany. In this workshop we want to highlight the connection between social and technical intervention in practice. For discussion in the workshop we introduce our first detailed findings on development and usage of the mesh network.

\subsection{How the design of the OLPC XO-1 may support the social structure of an intercultural community}

Anne Weibert

University of Siegen

Abstract: In this paper, we discuss how the technical features and design of the OLPC XO-1 may match with and support the interaction of children and adults in an intercultural computer club "come_IN", located in a culturally and socially diverse neighborhood. Originally designed for the usage by children in developing countries around the world, the technical design of the so called "100 \$ Laptop" follows constructionist thinking, aiming to enable especially children to freely explore, experiment and express themselves. For discussion we put this design in perspective with ideas and expectations that children, parents and tutors voiced in ten narrative interviews about their experiences in the intercultural computer clubs "come_IN" to distill the possibilities a future usage of the OLPC XO-1 may offer there.

\subsection{Restrictions and Constraints in Mobile Narratives for Place-based Community Engagement}

Kevin Wiesner ${ }^{1}$, Marcus Foth ${ }^{1}$, Mark Bilandzic ${ }^{2}$, Helmut Krcmar ${ }^{2}$
${ }^{1}$ Queensland University of Technology, Australia

${ }^{2}$ Center for Digital Technology and Management, Technische Universität München

Abstract: The usage of the mobile Internet increased tremendously within the last couple of years, and thereby the vision of accessing information anytime, anywhere became more realistic and a dominant design principle for providing content. However, this paper presents work-in-progress that challenges this paradigm of unlimited and unrestricted access, and explores and tests how constraints and restrictions may positively influence the motivation and enticement of mobile users to engage with location-specific content. Restrictions, such as a particular time or location that enables a user to access content, may be used to foster community participation and engagement, as well as to support locative media production and to enhance the user's experience. In the end, we outline the timeline of our current work and further studies planned in order to verify our hypothesis.

\section{REFERENCES}

[1] http://en.wikipedia.org/wiki/Locative media

[2] Willis, K., Chorianopoulos, K., Struppek, M., Roussos, G (2009 to appear). Shared Encounters. Springer, UK.

[3] Brown, B., A. Taylor, S. Izadi, A. Sellen, and J. Kaye (2007) Locating Family Values: A Field Trial of the Whereabouts Clock. In: Proc. of UBICOMP 2007 Insbruck, Austria. Springer, 354-371.

[4] Giles, T., Marienek, M., Willis, K. and Geelhaar, J. 2007. Hide and Seek. ACM MM 07, Germany, 481-484.

[5] Taylor, N., Cheverst, K., Fitton, D., Race, N. J., Rouncefield, M., and Graham, C. 2007. Probing communities: study of a village photo display. In proc. OZCHI '07, 17-24.

[6] Gaver, B., Dunne, T., and Pacenti, E. 1999. Design: cultural probes. Interactions $6,1,21-29$.

[7] Cheverst, K., Clarke, K., Fitton, D., Rouncefield, M., Crabtree, A., and Hemmings, T. 2002. SPAM on the menu: the practical use of remote messaging in community care. SIGCAPH Comput. Phys. Handicap, pp. 73-74.

[8] Dörner, C., Heß, J., and Pipek, V. 2008. Fostering userdeveloper collaboration with infrastructure probes. In CHASE '08. ACM, New York, NY, 48-44.

[9] Büscher, M., Gill, S., Mogensen, P., and Shapiro, D. 2001. Landscapes of Practice: Bricolage as a Method for Situated Design. CSCW 10, 1, 1-28.

[10] Cheverst, K., N. Taylor, M. Rouncefield, A. Galani and C. Kray. 2008. The Challenge of Evaluating Situated Display based Technology Interventions Designed to Foster 'Sense of Community', In proc. of USE '08, South Korea.

[1] Axup, J., Viller, S., MacColl, I., and Cooper, R. 2006. Lo-Fi Matchmaking: A Study of Social Pairing for Backpackers. In proc. Ubicomp 2006, Springer, Berlin, 351 - 3 